\title{
Primeiro registro de Trypanosoma vivax em bovinos no Estado do Rio Grande do Sul, Brasil
}

\author{
First report of Trypanosoma vixax in bovines in the State of Rio Grande do Sul, Brazil
}

\author{
Aleksandro Schafer da Silva' ${ }^{\mathrm{I}}$ Marcio Machado Costa ${ }^{\mathrm{I}}$ Mauro Flores Polenz ${ }^{\mathrm{II}}$ \\ Carlos Henrique Polenz ${ }^{\mathrm{III}}$ Marta Maria Geraldes Teixeira ${ }^{\mathrm{IV}}$ Sonia Terezinha Dos Anjos Lopes ${ }^{\mathrm{V}}$ \\ Silvia Gonzalez Monteiro ${ }^{\mathrm{V} *}$
}

\begin{abstract}
RESUMO
Este estudo teve o objetivo de relatar a ocorrência de Trypanosoma vivax no Sul do Brasil. O protozoário foi diagnosticado em esfregaço sanguíneo de um bovino e a identificação baseada na morfologia das formas tripomastigotas e confirmada pela técnica de reação em cadeia de polimerases (PCR). O animal infectado apresentou sintomatologia compatível com a forma nervosa da infecção por T. vivax. Outros bovinos que compartilhavam o mesmo ambiente apresentaram resultados negativos para $\boldsymbol{T}$. vivax por PCR. Este é o primeiro registro de T. vivax no Estado do Rio Grande do Sul e na região Sul do Brasil.
\end{abstract}

- NOTA-
Palavras-chave: tripanossomose, bovinos, sinais clínicos.

\section{ABSTRACT}

This study aimed at reporting the occurrence of Trypanosoma vivax in southern Brazil. The protozoan was diagnosed through peripheral blood smear evaluation of a bovine and confirmed by the evaluation of the trypomastigote forms morphology and by the Polimerase Chain Reaction (PCR). The animal showed clinical signs similar to the nervous form of the infection by $\mathbf{T}$. vivax. Negative results for $\mathbf{T}$. vivax were found in other bovines grazing in the same paddock. This is the first report of T. vivax in the state of Rio Grande do Sul and in the southern region of Brazil.

Key words: trypanosomiasis, bovines, clinical signs.
A tripanossomose causada por Trypanosoma vivax é de grande importância econômica no continente africano, onde esse parasita é transmitido pela mosca tsétsé para ruminantes, ocasionando infecções agudas e crônicas, que podem acarretar alterações hematológicas severas e mortalidade dos animais (ANOSA, 1983; GARDINER, 1989). NaAmérica do Sul, a transmissão da infecção por $T$. vivax é mecânica e atribuída, principalmente, a tabanídeos. Esta tripanossomose é altamente prevalente nas regiões Norte e Central (Pantanal) do Brasil, onde é, geralmente, assintomática (SHAW \& LAINSON, 1972; PAIVA et al., 2000; JONES \& DÁVILA, 2001; CORTEZ et al., 2006). Entretanto, alterações hematológicas e nervosas, que podem levar a morte, além de abortos e alterações na reprodução, foram descritas em bovinos, ovinos e caprinos infectados por T. vivax (SILVA et al., 1996; BATISTA et al., 2006; 2007; 2008a,b).

$\mathrm{O}$ curso da infecção por $\boldsymbol{T}$. vivax varia entre as cepas de parasitos isolados, bem como as espécies e raças de ruminantes hospedeiros (CORTEZ et al., 2006; BATISTA et al., 2006; 2007; 2008). Em bovinos infectados naturalmente com T. vivax no Brasil (Pantanal), foram observados sinais clínicos como

\footnotetext{
'Programa de Pós-graduação em Medicina Veterinária, Universidade Federal de Santa Maria (UFSM), Santa Maria, RS, Brasil.

${ }^{\text {IIC }}$ urso de Medicina Veterinária, UFSM, Santa Maria, RS, Brasil.

IIIMédico Veterinário autônomo, Videira, SC, Brasil.

IV Departamento de Parasitologia, Universidade de São Paulo (USP), São Paulo, SP, Brasil

vepartamento de Microbiologia e Parasitologia, UFSM, Santa Maria, Campus Universitário, Camobi, Km 9, Prédio 20, sala 4232, 97105-900, Santa Maria, RS, Brasil. E-mail: sgmonteiro@uol.com.br. *Autor para correspondência.
} 
anemia, leucopenia, lacrimejamento e fraqueza progressiva, marcada por perda de peso e abortos (SILVA et al., 1999). No primeiro surto no Nordeste do Brasil (Paraíba), em gado leiteiro, com diagnóstico de T. vivax, os animais infectados apresentaram febre, anemia e perda de peso. Todos os bovinos com sinais nervosos morreram, e outros abortaram ou pariram um bezerro que morreu logo após o parto (BATISTA et al., 2007). Antes deste estudo, nenhum caso de infecção causada por T. vivax havia sido descrito no Sul do Brasil. Dessa forma, o registro do primeiro caso deste flagelado em bovino do Estado do Rio Grande do Sul se faz oportuno.

No município de São Pedro, Estado do Rio Grande do Sul, Brasil, foi avaliado um bovino, fêmea, sem raça definida, com 2,5 anos de idade, que se encontrava no quinto mês de gestação. No exame clínico, o animal apresentou sinais clínicos inespecíficos como hiporexia, hipertermia, fraqueza, desidratação, mucosas ictéricas, secreção vaginal, agressividade, atrofia muscular dos membros pélvicos, incoordenação motora, dificuldade em levantar-se e manter-se em pé, além de adotar a posição de "cão sentado" (Figura 1). Segundo o proprietário, o animal era mantido em área com vegetação nativa e próxima a aguadas, junto a outros bovinos. Amostras de sangue de quatro bovinos que compartilhavam a mesma área foram utilizadas para esfregaços sanguíneos, hemograma e análises bioquímicas. As amostras de sangue colhidas com anticoagulante também foram preservadas em etanol (v/v) e utilizadas para extração de DNA. As preparações de DNA foram submetidas a um ensaio de PCR (reação em cadeia da polimerase) específico para T. vivax e altamente sensível, padronizado por CORTEZ et al. (2009). Esse método de PCR, que distingue T. vivax de T. evansi, T. theileri e de outros tripanossomas de bovinos, tem como alvo sequências repetitivas de genes que codificam cisteíno-proteases (Catepsina L) e foi realizado utilizando como iniciadores os oligonucleotídeos TviCatL1 e DTO155 em condições de reação descritas em CORTEZ et al. (2009).

Os seguintes parâmetros hematológicos foram analisados: número de hemácias, hematócrito (Ht), concentração de hemoglobina $(\mathrm{Hb})$, volume corpuscular médio (VCM), concentração de hemoglobina corpuscular média ( $\mathrm{CHCM})$, proteínas plasmáticas totais e leucócitos totais. A contagem de hemácias e a determinação da concentração de hemoglobina foram realizadas em aparelho de contagem celular eletrônico, marca CELM - modelo CC 550. Nas análises bioquímicas, foram realizadas a dosagem de alanino aminotransferase (ALT) e aspartato aminotransferase (AST), gama glutamil transferase
(GGT), creatina quinase (CK), proteína total, albumina, globulinas, creatinina e uréia. Para as dosagens bioquímicas, foram utilizados o analisador semiautomático BioPlus (Bio-200) e kits comerciais.

O diagnóstico inicial de T. vivax foi baseado na análise morfológica de formas tripomastigotas em esfregaços de sangue corados com Giemsa. Embora tenham sido observadas poucas formas tripomastigotas, foi possível observar características morfológicas de T. vivax, tais como o tamanho do corpo e da membrana ondulante e a presença e posição do cinetoplasto na porção final da extremidade posterior, que permitem distinguir essa espécie de T. evansi e $\mathbf{T}$. theileri (VENTURA et al., 2000; RODRIGUES et al., 2003). A confirmação do diagnóstico foi realizada por PCR (CORTEZ et al., 2009), com a amplificação de um fragmento de DNA de $\sim 177 \mathrm{bp}$, também observado em DNA de T. vivax (isolado do Pantanal) utilizado como controle positivo. Esse fragmento de DNA não é amplificado com DNA de T. evansi e T. theileri. Como controles negativos da PCR, foram testadas amostras de DNA de sangue de bovinos não infectados previamente selecionadas (CORTEZ et al., 2009).

Sessenta dias após o diagnóstico, o animal infectado por T. vivax, que não foi medicado, foi reexaminado. O animal, embora em bom estado nutricional e sem parasitemia detectável em esfregaços, apresentava dificuldade de locomoção. Aos nove meses de gestação, nasceu um bezerro fraco que morreu dois dias após o parto. A fêmea voltou a apresentar hipertermia, fraqueza muscular, e esfregaços sanguíneos revelaram o retorno da parasitemia por $\mathbf{T}$. vivax (Figura 1D). Os sinais clínicos observados no bovino analisado neste estudo, inclusive incoordenação motora e o nascimento de bezerro que morreu logo após o parto, são compatíveis com os descritos em estudos experimentais, assim como em outros casos de tripanossomose por T. vivax ocorridos no Brasil (BATISTA et al., 2007; 2008b; CARVALHO et al., 2008). Alterações neurológicas são também descritas em bovinos e equinos infectados com T. evansi (RODRIGUES et al., 2005; DA SILVA et al., 2007). Esta espécie é mais comum no Pantanal, mas tem sido encontrada no Sul do Brasil, onde foram descritos casos de infecção em cães e equinos (COLPO et al., 2005; RODRIGUES et al., 2005). Bovinos infectados com $\boldsymbol{T}$. evansi foram diagnosticados recentemente no Estado de Santa Catarina, Sul do Brasil (DA SILVA et al., 2007). Uma vez confirmada a infecção por T. vivax e a ausência de T. evansi no animal examinado, suspeitou-se de um surto com infecção assintomática ou com sintomatologia inespecífica. Porém, essa suspeita não se confirmou devido aos resultados negativos de PCR dos demais animais da mesma propriedade. 


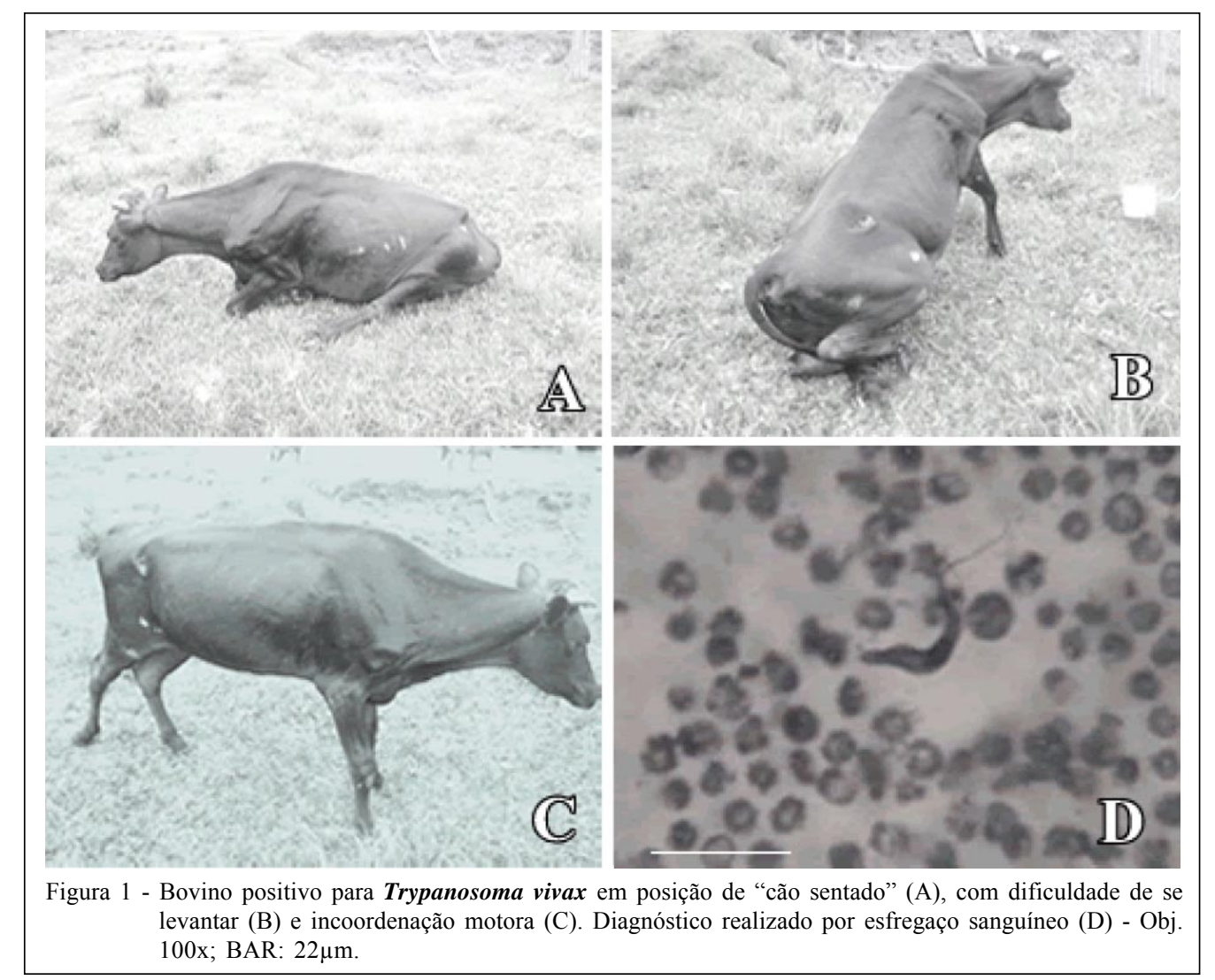

O hemograma do animal infectado não apresentou alterações, diferindo, portanto, dos casos de infecção sintomática descritos no Brasil, que revelaram anemia e leucopenia em ruminantes parasitados por T. vivax (SILVA et al., 1996; 1999; BATISTA et al., 2006; 2007; 2008a,b; CARVALHO et al., 2008). As funções hepáticas, renais e a atividade enzimática muscular não foram afetadas pela infecção por esse protozoário. Porém, foi observado aumento dos níveis de proteínas totais e globulinas e, concomitantemente, redução na albumina.

A fim de esclarecer a origem do caso de infecção por T. vivax descrito neste estudo no RS, foi realizada uma investigação epidemiológica na propriedade onde o animal infectado vivia. Foi constatado que a área é muito propícia ao desenvolvimento de tabanídeos e outras moscas hematófagas, que são encontrados em grande número próximo a um rio da propriedade. Segundo o fazendeiro, o bovino parasitado nunca havia saído da propriedade, nos últimos dois anos nenhum outro animal havia sido introduzido no rebanho e os ruminates da propriedade haviam sido adquiridos no mesmo município, área onde nunca havia sido descrita infecção por T. vivax. Entretanto, nada se sabe sobre os animais das propriedades vizinhas. Na propriedade estudada, não são criados cabras e búfalos, conhecidos reservatórios assintomáticos, nem ovelhas, que são bastante suscetíveis à infecção por T. vivax. Cervídeos silvestres, observados na região central do Estado do RS, podem ser reservatórios naturais de T. vivax (BATISTA et al., 2006; 2008; RODRIGUES et al., 2008). A detecção desse caso isolado de T. vivax no centro do RS, distante das áreas endêmicas do Brasil, sugere que esse parasita pode ter sido introduzido e estar distribuído nessa região há muito tempo, não tendo sido previamente diagnosticado devido ao desenvolvimento, até esse estudo, apenas de quadros clínicos assintomáticos.

Até recentemente, os estudos sobre T. vivax no Brasil foram conduzidos somente em áreas endêmicas, principalmente após surtos de doença aguda, como ocorridos no Pantanal (SILVA et al., 1996; VENTURA et al., 2001; MADRUGA et al., 2006; CORTEZ et al., 2006). Porém, os relatos recentes de infecção por T. vivax em bovinos da Paraíba (BATISTA et al., 2007), Maranhão (GUERRA et al., 2008) e Minas Gerais (CARVALHO et al., 2008) demonstraram que os veterinários estão mais atentos aos sinais clínicos, que podem ser muito variados, e preparados para fazer o

Ciência Rural, v.39, n.8, nov, 2009. 
diagnóstico de tripanossomoses. Entretanto, muito cuidado deve ser tomado no diagnóstico diferencial de espécies baseado apenas na morfologia de formas do sangue, uma vez que três espécies de Trypanosoma podem ser encontradas com frequência em ruminantes no Brasil, muitas vezes em infecções mistas: T. vivax, T. evansi e T. theileri. Outro fator bastante limitante no diagnóstico de tripanossomoses em bovinos é o número reduzido desses parasitas no sangue, exigindo a utilização de métodos sensíveis e específicos como a PCR para a detecção desses parasitas (VENTURA et al., 2001; DAVILA et al., 2003; RODRIGUES et al., 2003; CORTEZ et al., 2009).

Devido à total falta de estudos na região, somente um estudo epidemiológico mais aprofundado, a fim de avaliar a ocorrência de $T$. vivax em áreas vizinhas, poderia ajudar a esclarecer o primeiro caso de infecção por esse protozoário no RS descrito neste estudo.

\section{AGRADECIMENTOS}

Ao doutorando Herakles Antonio Garcia Perez, da Universidade Federal de São Paulo, pelo auxílio do diagnóstico por PCR da tripanossomose.

\section{REFERÊNCIA}

ANOSA, V.O. Diseases produced by Trypanosoma vivax in ruminants, horses and rodents. Veterinary Medicine, v.30, n.10, p.717-741, 1983. Disponível em: <http://www.ncbi.nlm.nih.gov/ pubmed/6367315>. Acesso em: 29 nov. 2008.

BATISTA, J.S. et al. Infecção experimental por Trypanosoma vivax em ovinos. Pesquisa Veterinária Brasileira, v.26, n.1, p.31-37, 2006. Disponível em: <http://www.scielo.br/ s c i e lo.php?script=sci arttext \& pid = S 0100 736X2006000100007>. Acesso em: 12 jan. 2009. doi: 10.1590/ S0100-736X2006000100007.

BATISTA, J.S. et al. Trypanosomiasis by Trypanosoma vivax in cattle in the Brazilian semiarid: description of an outbreak and lesions in the nervous system. Veterinary Parasitology, v.143, n.2, p.174181, 2007. Disponível em: < http://www.sciencedirect.com/ science?_ob=ArticleURL\&_udi=B6TD7-4KVXPVK$1 \&$ user $=10 \&$ rdoc $=1 \& \mathrm{fmt}=\&$ orig $=$ search $\&$ sort $=\mathrm{d}$ $\&$ docanchor $=\&$ view $=$ c \&_searchStrId $=94 \overline{6} 74530$ 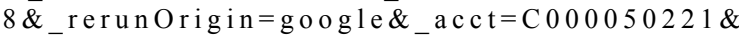 _ ve r s i o n $=1 \&$ _ u r 1 Vers i o $n=0 \&$ _ u s e r i d $=$ 10\&md5=92001 cc62d52 d45760d26a5ddd12a504>. Acesso em: 12 jan. 2009. doi: 10.1016/j.vetpar.2006.08.017.

BATISTA, J.S. et al. Infecção experimental em caprinos com Trypanosoma vivax. Ciência Animal Brasileira, v.9, n.3, p.673-685, 2008a. Disponível em: < http://www.revistas.ufg.br/ index.php/vet/article/viewArticle/544>. Acesso em: $11 \mathrm{jan}$. 2009 .

BATISTA J.S. et al. Aspectos clínicos, epidemiológicos e patológicos da infecção natural em bovinos por Trypanosoma vivax na Paraíba. Pesquisa Veterinária Brasileira, v.28, n.1, p.63-69, 2008b
Disponível em: <http://www.scielo.br/scielo.php?pid=S0100$736 \mathrm{X} 2008000100010 \& \mathrm{script}=\mathrm{sci}$ arttext\&tlng=pt $>$. Acesso em: 11 jan. 2009. doi: 10.1590/S0100-736X2008000100010.

CARVALHO, A.U. et al. Ocorrência de Trypanosoma vivax no estado de Minas Gerais. Arquivos Brasileiros de Medicina Veterinária e Zootecnia, v.60, n.3, p.769-771, 2008. Disponível em: $<$ http://www.scielo.br/scielo.php?script=sci_arttext\&pid=S010209352008000300037>. Acesso em: 11 jan. 2009. doi: 10.1590/ S0102-09352008000300037.

COLPO, C.B. et al. Infecção natural por Trypanosoma evansi em cão no Rio Grande do Sul. Ciência Rural, v.35, n.3, p.717-719, 2005. Disponível em: <http://www.scielo.br/ s cielo.php? script=sci_arttext \& pid=S 0103 $84782005000300038>$. Acesso em: 11 jan. 2009. doi: 10.1590/ S0103-84782005000300038

CORTEZ, A.P. et al. The taxonomic and phylogenetic relationships of Trypanosoma vivax from South America and Africa. Parasitology, v.133, n.2, p.159-169, 2006. Disponível em: $<$ https://www.researchgate.net/publication/ 7131693 The_taxonomic_and_phylogenetic_rela tionships_of_Trypanosoma_vivax_from_South_America_and_Africa $>$. Acesso em: 12 jan. 2009. doi: 10.1017/S0031182006000254.

CORTEZ, A.P. et al. Cathepsin L-like genes of Trypanosoma vivax from Africa and South America - characterisation, relationships and diagnostic implications. Molecular and Cellular Probes, v.23, n.1, p.44-51, 2009. Disponível em: $<$ http://www.sciencedirect.com/ science? ob=ArticleURL\& udi=B6WNC-4V0MWYK$1 \&$ _user $=10 \&$ rdoc $=1 \&$ fmt $=\&$ \&orig $=$ search $\&$ sort $=\mathrm{d}$ $\&$ docanchor $=\&$ view $=$ c \&_searchStrId $=946755473$ $\&$ rerunOrigin $=$ google \&_ac ct $=$ C 0000050221

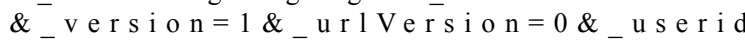
$=10 \& \mathrm{md} 5=\mathrm{ef} 9 \mathrm{ad} 1237 \mathrm{db} 3 \mathrm{fc} 5 \mathrm{bef1d} 7 \mathrm{c} 441 \mathrm{e} 70 \mathrm{a} 983>$. Acesso em: 12 jan. 2009. doi: 10.1016/j.mcp.2008.11.003.

DA SILVA, A.S. et al. Ocorrência de Trypanosoma evansi em bovinos de uma propriedade leiteira no município de Videira SC. Acta Scientiae Veterinariae, v.35, n.3, p.373-376, 2007. Disponível em: <http://www.ufrgs.br/actavet/35-3/artigo750.pdf $>$. Acesso em: 19 jan. 2008.

DÁVILA, A.M.R. et al. Using PCR for unraveling the cryptic epizootiology of livestock trypanosomosis in the Pantanal, Brazil. Veterinary Parasitology, p.117, n.1-2, p.1-13, 2003. Disponível em: <http://www.sciencedirect.com/ science? ob=ArticleURL\& udi=B6TD7-49SFGR1$1 \&$ \& s e r $=10 \&$ rd o c $=1 \&$ f m t $=\&$ orig $=\mathrm{se}$ a r c h \&_s or t $=$ d \&_d o c a n c hor $=\&$ vi e w $=$ c\&_searchStrId $=946757541 \&$ rerunOrigin $=$ g o o g 1 e \&_a c c t $=$ C $000050221 \&$ \&_version $=1 \&$ urlVersion $=0 \AA-$ userid $=10 \& \mathrm{md} 5=6 \mathrm{fbc} 560 \mathrm{f} 52 \mathrm{~b} 70 \mathrm{ab} 58 \mathrm{af} 9721994527 \mathrm{cb} 7>$. Acesso em: 19 jan. 2009. doi:10.1016/j.vetpar.2003.08.002.

GARDINER, P.R. Recent studies of the biology of Trypanosoma vivax. Advances Parasitology, v.28, n.2, p.229-317, 1989. Disponível em: <http://www.ncbi.nlm.nih.gov/pubmed/2683616>. Acesso em: 15 abr. 2007.

GUERRA, R.M.S.N.C. et al. Biometry of Trypanosoma vivax found in a calf in the state of Maranhão, Brazil. Ciência Rural, v.38, n.3, p.833-835, 2008. Disponível em: <http:// w w w. s c i e 1 o.b r / s c i e 1 o.p h p ? p i d = S 0103 84782008000300041\&script $=$ sci_arttext $>$. Acesso em: $15 \mathrm{dez}$. 2009. doi: 10.1590/S0103-84782008000300041. 
JONES, T.W.; DA'VILA, A.M.R. Trypanosoma vivax out of Africa. Trends Parasitology, v.17, n.1, p.99-101, 2001. Disponível em: <http://www.ingentaconnect.com/content/els/ 14714922/2001/00000017/00000002/art01777>. Acesso em: 12 jan. 2009. doi: 10.1016/S1471-4922(00)01777-3.

MADRUGA, C.R. et al. The development of an enzymelinked immunosorbent assay for Trypanosoma vivax antibodies and its use in epidemiological surveys. Memórias do Instituto Oswaldo Cruz, v.101, n.7, p.801-807, 2006. Disponível em: <http://bases.bireme.br/cgi-bin/wxislind.exe/iah/online/ ? Is is Script=iah/iah.xis \& s rc =google \&base $=$ L I L A C S\&lang=p\&nextAction=lnk\&exprSearch=439467\&indexSearch=ID $>$. Acesso em: 12 jan. 2009.

PAIVA, F. et al. Trypanosoma vivax em bovinos no Pantanal do Mato Grosso do Sul, Brasil. I. Acompanhamento clínico, laboratorial e anatomo-patológico de rebanhos infectados. Revista Brasileira de Parasitologia Veterinária, v.9, n.2, p.135-141, 2000. Disponível em: <http://www.ufrrj.br/rbpv/ 922000/c92135_141.pdf>. Acesso em: 12 jan. 2009.

RODRIGUES, A.C. et al. Brazilian isolates of Trypanosoma (Megatrypanum) theileri: diagnosis and differentiation of isolates from cattle and water buffalo based on biological characteristics and randomly amplified DNA sequences. Veterinary Parasitology, v.116, n.3, p.185-207, 2003. Disponível em: $<\mathrm{ht} \mathrm{p}: / / \mathrm{w}$ w w s c e n c e d i e c t c o m science?_ob=ArticleURL\&_udi=B6TD7-49546F 5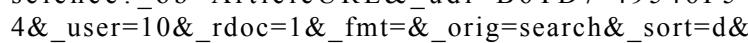 _docanchor $=\&$ view $=\bar{c} \&$ s e a rchStrId $=9 \overline{4} 677115$ $\overline{4} \&$ \&_rerunOrigin $=$ goog 1 e \&_a c c t $=$ C 0000050221 $\&_{-}$version $=1 \&$ \& ur 1 Vers i on $=0 \&$ \& us erid $=1$ $0 \& \mathrm{md} 5=8642 \mathrm{a} 76 \mathrm{fb} 7 \mathrm{dd} 466 \mathrm{c} 0 \mathrm{a} 618 \mathrm{bcce} 3 \mathrm{~d} 53038>$. Acesso em: 12 jan. 2009. doi:10.1016/S0304-4017(03)00236-X.

RODRIGUES, A. et al. Outbreaks of Trypanosomiasis in horses by Trypanosoma evansi in the state of Rio Grande do Sul, Brazil: epidemiological, clinical, hematological, and pathological aspects. Pesquisa Veterinária Brasileira, v.25, n.4, p.239-249, 2005. Disponível em: <http://www.scielo.br/scielo.php?pid=S0100736X2005000400010\&script $=$ sci_arttext $>$. Acesso em: 12 jan. 2009. doi: 10.1590/S0100-736X2005000400010.

RODRIGUES, A.C. et al. Phylogenetic analysis of Trypanosoma vivax supports the separation of South American/West African from East African isolates and a new $\boldsymbol{T}$ vivax-like genotype infecting a nyala antelope from Mozambique. Parasitology, 135: 131728. 377, 2008. Disponível em: <http://journals.cambridge.org/ action $/$ displayAbstract? fromPage $=$ online $\&$ aid $=2205356>$. Acesso em: 12 jan. 2009. doi:10.1017/S0031182008004848.

SHAW, J.J.; LAINSON, R. Trypanosoma vivax in Brazil. Annals of Tropical Medicine Parasitology, v.66, n.1, p.2533,1972 .

SILVA, R. et al. Outbreak of trypanosomiasis due to Trypanosoma vivax (Ziemann, 1905) in bovine of the Pantanal Brazil. Memórias do Instituto Oswaldo Cruz, v.52, n.5, p.561-562, 1996. Disponível em: <http://memorias.ioc.fiocruz.br/915/ 3088.html>. Acesso em: 12 jan. 2009.

SILVA, R.A.M.S. et al. Hematology of natural bovine trypanosomosis in the Brazilian Pantanal and Bolivian Wetlands. Veterinary Parasitology, v.85, n.1, p.87-93, 1999. Disponível em: <http:// www.sciencedirect.com/science?_ob=ArticleURL\&_udi=B6TD73 WYHTD1-9\&_user $=10 \&$ rdoc $=1 \&$ fmt $=\&$ \& orig $=$ search $\&$ sort $=$ d\&_docanchor $=\& v i e w=c \&$ search $\overline{S t r I d}=946777 \overline{4}$ $16 \&$ r e runOrigin $=$ g o o g le \&_a c c t $=$ C 0000 $502221 \&$ \& e r s i o $n=1 \&$ u r 1 V e r s i o $n$ $=0 \&$ \&userid $=10$ \& md5 $=433715 \mathrm{~d} 18859 \mathrm{ea} 713432 \mathrm{f} 6 \mathrm{e} 8 \mathrm{f} 961 \mathrm{c} 46 \mathrm{e}>$. Acesso em: 12 jan. 2009. doi: 10.1016/S0304-4017(99)00081-3.

VENTURA, R.M. et al. Molecular and morphological studies of Brazilian Trypanosoma evansi stocks: the total absence of kDNA in 417 trypanosomes from both laboratory stocks and naturally infected domestic and wild mammals. Journal of Parasitology, v.86, n.10, p.1289-1298, 2000. Disponível em: <http:// ww w. bioone.org/doi/abs/10.1645/0022$3395 \% 282000 \% 29086 \% 5 \mathrm{~B} 1289 \% 3 \mathrm{AMAMSOB} \% 5 \mathrm{D} 2.0 . \mathrm{CO} \% 3 \mathrm{~B} 2>$. Acesso em: 12 jan. 2009. doi: 10.1645/00223395(2000)086[1289:MAMSOB]2.0.CO;2.

VENTURA, R.M. et al. Trypanosoma vivax: characterization of the spliced-leader gene for a Brazilian stock and speciesspecific detection by PCR amplification of an intergenic space sequence. Experimental Parasitology, v.99, n.1, p.37-48, 2001. Disponível em: <http://www.ingentaconnect.com/ content/ap/pr/2001/00000099/00000001/art04641>. Acesso em: 12 jan. 2009. doi: 10.1006/expr.2001.4641. 